\title{
Surgical Treatment of Adult Moyamoya Disease with Combined STA-MCA Bypass and EDAS: Demonstration of Technique in Video Presentation
}

\author{
Erişkin Moyamoya Hastallğınn STA-MCA Bypass ve EDAS ile Cerrabi \\ Tedavisi:Tekniğin Video Gösterimi
}

Yiping LI, Ulas CIKLA, Christopher BAGGOTT, Tevfik YILMAZ, Clifford CHAO, Mustafa K BASKAYA

University of Wisconsin Medical School, Department of Neurological Surgery, USA

Corresponding Author: Mustafa K BASKAYA / E-mail: m.baskaya@neurosurgery.wisc.edu

9

To watch the surgical videoclip, please visit http://turkishneurosurgery.org.tr/images/12829-video.mp4

\begin{abstract}
The natural history of Moyamoya disease (MD) is variable. Moyamoya disease in children mostly presents with progressive ischemic complications and in adulthood it tends to present with hemorrhage. Surgical strategies depend on augmenting cerebral blood flow to the anterior cerebral circulation. Revascularization is the mainstay treatment for MD. We introduce a 31 year old female with a history of MD and leftsided revascularization as a child, who presented with headache, confusion, and worsening left sided weakness. Cranial computed tomography (CT) showed a right sided putaminal hemorrhage. Cerebral angiogram with selective external runs revealed MD, hypoplastic parietal branch of the superficial temporal artery (STA) on the right side and previous revascularization on the left side. Thus, our decision was made to perform a bypass with the frontal branch of the STA to an M3-M4 segment of the middle cerebral artery and an encephaloduroarteriomyosynangiosis with the parietal branch of the STA. The patient's postoperative course was uneventful. Postoperative CT angiogram confirmed patency of bypass. This technique provides immediate revascularization and seems to provide risk reduction for ischemic and hemorrhagic stroke. We review the natural history and surgical treatment of MD along with a case presentation in which surgical technique is demonstrated in video. KEYWORDS: Moyamoya disease, Bypass, Encephaloduroarteriomyosynangiosis (EDAS), Revascularization
\end{abstract}

ÖZ

Moyamoya hastalığının (MH) doğal seyri değişkenlik gösterir. Çocuklarda genellikle ilerleyici iskemik komplikasyonlarla karşımıza çıkarken erişkinlerde kanamayla görülme eğilimindedir. Cerrahi stratejiler ön beyin kan akımını desteklemeye yöneliktir. MH'nın temel tedavisi yeniden kanlanmanın sağlanmasıdır. 31 yaşında çocukluk döneminde sol taraf yeniden kanlandırma hikayesi olan bayan hasta başağrısı, konfüzyon ve sol tarafta güçsüzlük ile başvurdu. Beyin tomografisinde (BT) sağ putaminal kanama saptandı. Beyin karotis anjiyografisinde sağ tarafta MH ile uyumlu görünümle yüzeysel temporal arterin (YTA) paryetal dalının hipoplastik olduğu ve sol tarafta daha önce yapılan yeniden kanlanma alanı görüntülendi. Bu nedenle YTA'in frontal dalı ile orta serebral arterin M3-M4 bölümüne bypass ve YTA'in paryetal dalına encephaloduroarteriomyosynangiosis (EDAS) yapılmasına karar verildi. Cerrahi sonrası hastada herhangi bir sorun görülmedi. Cerrahi sonrası BT anjiyogramda bypassın açık olduğu gösterildi. Bu yöntem erken dönemde yeniden kanlanmayı sağlayarak iskemik ve hemorajik inme riskini azaltmaktadır. Çalışmada, MH'nın doğal seyri ve cerrahi tedavisi gözden geçirilerek cerrahi tekniğin video eşliğinde sunulduğu bir olgu ile tartışılmıştır..

ANAHTAR SÖZCÜKLER: Moyamoya hastalığı, Bypass, Encephaloduroarteriomyosynangiosis (EDAS), Yeniden kanlanma

\section{INTRODUCTION}

Moyamoya disease (MD) is a progressive steno-occlusive disease of the circle of Willis. Primarily, MD results in gradual stenosis of bilateral supraclinoid internal carotid arteries and subsequent compensatory proliferative pial collateral formation. This consequential pial collateralization forms a characteristic "puff of smoke" appearance on digital subtraction angiography and thus the disease was coined after the Japanese term "Moyamoya" which means "puff of smoke". Though the purpose of proliferative perforators and anastomotic branches are to provide collateral blood supply to the hypoperfused territories of the circle of Willis, these fragile vessels commonly occlude or leak resulting in both ischemic and hemorrhagic strokes (4).

There are many ways to categorize the severity of MD. The modified Suzuki classification defines MD severity based on the development of extensive collateral networks at the base of the brain and from the external carotid artery (26). This is 
the most widely used classification system and correlates with diminished cortical perfusion from the anterior circulation.

Because the etiology of MD is unknown, the traditional management of MD has been focused on prevention of hemorrhage and stroke by augmenting cerebral blood flow. The literature suggests that in addition to antiplatelet medications, both direct and indirect surgical revascularization techniques are effective in reducing the risk of ischemia and hemorrhage $(5,7,18,24)$. In this article, we review the natural history and surgical treatment of MD along with a case presentation in which surgical technique is demonstrated in video.

\section{CASE ILLUSTRATION WITH VIDEO PRESENTATION}

We introduce the case of a 31 year old female who presented with a history of MD and left-sided revascularization as a child. She also presented with headache, confusion, and worsening left sided weakness. Computed Tomography scan

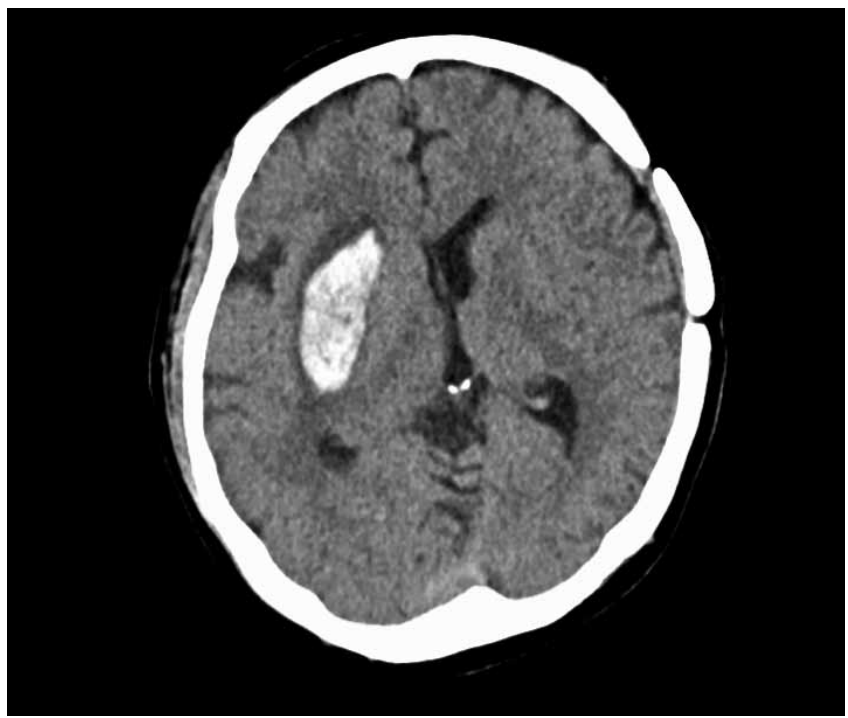

Figure 1: CT of head shows a right sided putaminal hemorrhage.
(CT) showed a right sided putaminal hemorrhage (Figure 1). Cerebral angiogram revealed supraclinoid internal carotid artery stenosis with a proliferative pial collateralization from the external carotid artery and posterior circulation consistent with MD (Figure $2 \mathrm{~A}, \mathrm{~B}$ ).

Cerebral angiogram with selective external runs also revealed that the parietal branch of the STA was hypoplastic (Figure 3). Thus, the decision was made to perform a bypass with the frontal branch of the superficial temporal artery (STA) to an M3-M4 segment of the middle cerebral artery (MCA) and an encephaloduroarteriomyosynangiosis (EDAS) with the parietal branch of the STA.

In such a procedure, the patient is placed in the supine position with the head turned to the contralateral side 20-30 degrees and slightly extended. An incision is marked directly over the STA branches mapped out by Doppler sonography. Dissection of the STA is performed under microscopic magnification and illumination. The scalp is retracted using fine fish-hooks and exposure of the artery is carried out using a combination of sharp and blunt dissection techniques.

First the main trunk of the STA, then the frontal and parietal branches of the STA are identified. The incision is extended posteriorly over the parietal branch to expose an appropriate length of STA for the EDAS procedure. The side branches of the parietal STA are cauterized and the artery is mobilized with a cuff of tissue from the galeal layer. The parietal STA is covered by nitroprusside soaked gelfoam and telfa patties and the dissection is now turned towards the frontal branch of the STA. The frontal branch of the STA is harvested in the same manner, again making sure there is adequate length for the bypass.

Next the temporalis muscle is divided, dissected, and retracted away from the underlying bone. A pterional craniotomy is created to expose the distal branches of the MCA emanating from the sylvian fissure. The dura is opened and the cortex is inspected for a suitable recipient M4 branch. Ideal recipients

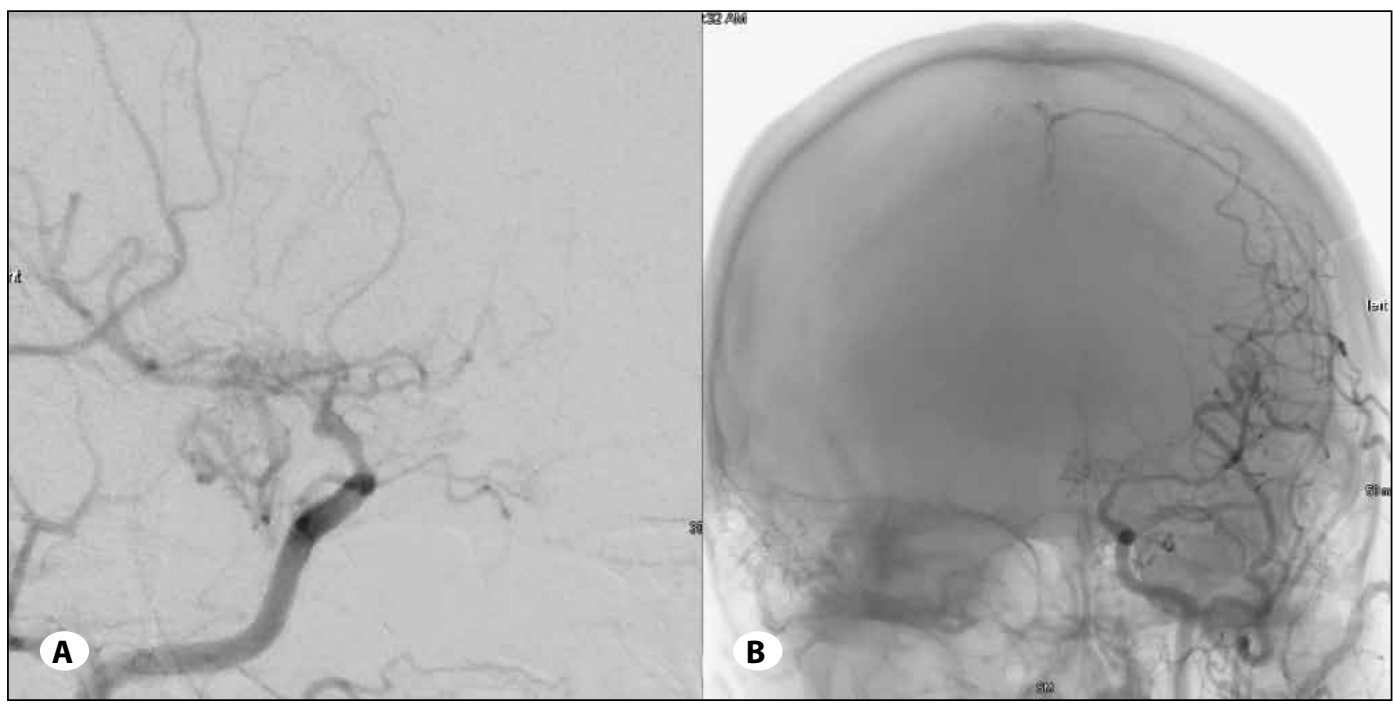

Figure 2: A) Right carotid angiogram reveals right supraclinoid internal carotid artery stenosis with a proliferative pial collateralization from the external carotid artery and posterior circulation consistent with Moyamoya disease.

B) Left carotid angiogram reveals previous revascularization performed when the patient was a child. 


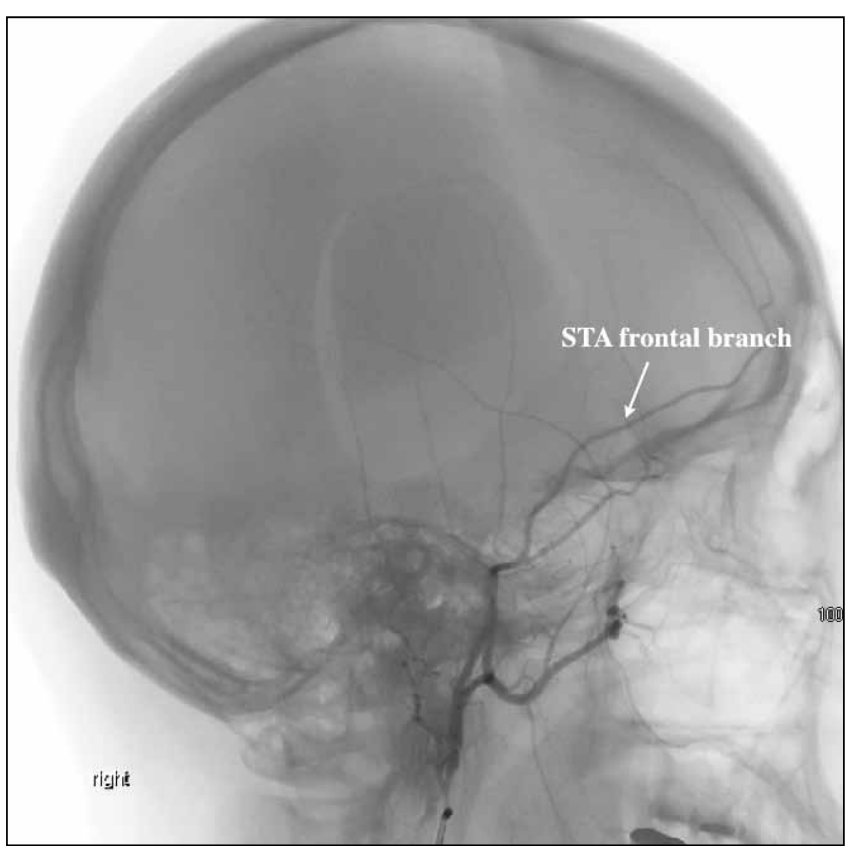

Figure 3: Cerebral angiogram with selective external carotid artery injection demonstrates frontal branch of STA with appropriate size for bypass and hypoplastic parietal branch of the STA.

are free from side branches and easily dissectible from the arachnoid.

Once the donor and recipient vessels are dissected free, the donor vessel is clipped with a temporary aneurysm clip, irrigated with heparinized saline, and placed on a telfa patty. Adventisectomy is performed in the distal end of the STA. The temporary clip is released periodically to prevent any intraluminal clot formation.

After preparing the recipient vessel, the frontal STA is irrigated with nitroprusside solution to prevent vasospasm. Next the donor artery is marked with blue dye, divided at an angle, and fish mouthed in order to prepare it for anastomosis. A 10-0 nylon suture on a non-cutting needle is placed through the apex of the donor vessel prior to clamping the recipient artery to facilitate anastomosis. Once the arteriotomy length is measured and the recipient branch is marked with blue dye and temporary clips are placed to interrupt blood flow for anastomosis, the small arteriotomy is performed using an ophthalmic knife and extended using micro-scissors. Next the heel of the donor is sutured to the end of the donor vessel to approximate the end to side anastomosis. The sutures are placed in an interrupted fashion. Upon completion of the anastomosis, the temporary clips are removed and hemostasis from the suture site is obtained with application of Surgicel. Both Indocyanine Green and micro-Doppler ultrasonography are used to confirm patency of the bypass.

Upon completion of the STA-MCA bypass, the pia/arachnoid over the cerebral cortex is opened and the proximal end of the frontal branch of STA is sutured with 10-0 nylon onto the arachnoid membrane. This allows for synangiosis between the donor STA and the cerebral cortex. This technique allows for concomitant STA-MCA bypass and EDAS procedures to be performed.

The parietal STA is similarly anchored to the arachnoid of the cerebral cortex after the underlying pia/arachnoid membranes have been opened. This technique stabilizes the graft and stimulates synangiosis.

Prior to closure, hemostasis is obtained using Surgicel and gelfoam patties. It is important to close the dura loosely as well as rongeur the craniotomy flap to prevent compression of the graft during closure. Post-operatively the patient should be started on an aspirin daily, blood pressure should be kept on the higher side of normal, and the graft site should be kept void of compression to prevent any chances of graft occlusion.

The patient's postoperative course was uneventful. Postoperative $C T$ angiogram confirmed patency of bypass (Figure $4 A, B)$.

\section{DISCUSSION}

The natural history of MD is extremely variable between patients. Depending on the etiology, MD may be slowly progressive with intermittent, rare, or no neurologic sequelae. In others the disease may progress rapidly with frequent and swift neurologic decline. Despite the robust variability of symptoms amongst patients, Moyamoya is inevitably progressive in a great majority of the affected population with a $73 \%$ rate of major deficit or death in children followed two years after diagnosis (19).

In general MD in children presents with progressive ischemic complications and up to two-thirds of cases will develop either ischemic or hemorrhagic complications if left untreated over a five-year period $(22,23)$. MD presenting in adulthood is less likely to be ischemic or as progressive as in the pediatric population but despite maximal medical therapy, over $20 \%$ of adult patients will also experience symptomatic progression. In adults, although there is a higher probability of experiencing hemorrhagic complications, gradual hypoperfusion can result in significant impairment in learning and memory as well (28). The cumulative ischemic effects on adults warrants aggressive intervention targeting both the ischemic and hemorrhagic complications of MD.

In patients who have had a previous ischemic or hemorrhagic event, Hallemeier et al. found a $65 \%$ risk of recurrent ipsilateral stroke at 5 years with medical therapy alone (7). The outcome is even worse in patients without medical or surgical treatment $(3,14)$. With surgical revascularization however, a recent meta-analysis estimated rates of symptomatic progression in these patients to be $2.6 \%$ after surgery (5). Several studies have followed patients with "asymptomatic" MD, which is to say patients without history of ischemic or hemorrhagic strokes and found an annual stroke risk of about 3\% per year $(7,12,29)$. Surgical intervention in patients presenting 


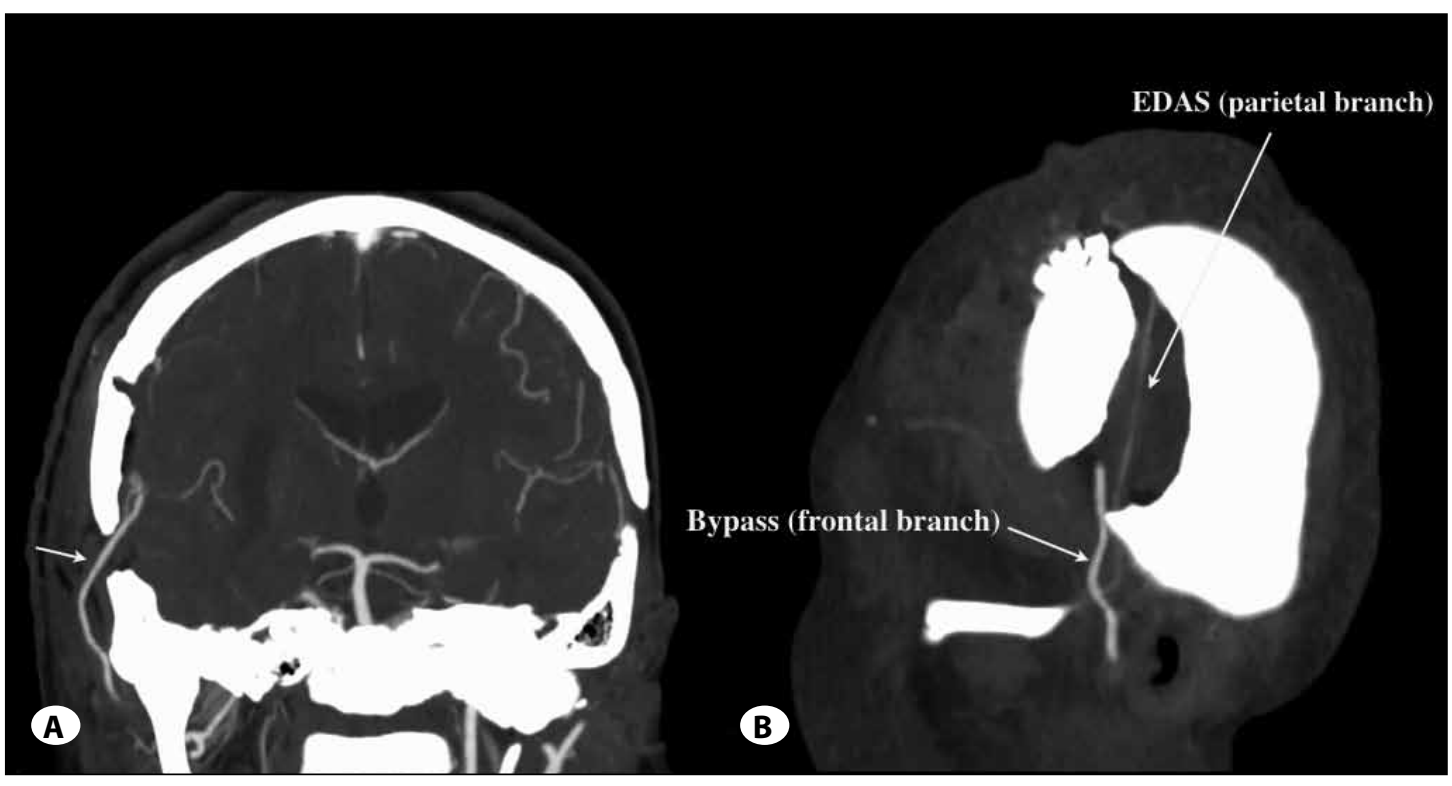

Figure 4:

A) Postoperative coronal CT angiogram confirms patency of bypass with the frontal branch of the STA. B) Sagittal CT angiogram reveals the parietal branch of the STA traveling from the trunk distally. with a previous ischemic or hemorrhagic event appears to reduce the risk more towards that of the natural history of asymptomatic patients. Surgical revascularization may also improve the impairments in cognition and memory in adults with MD (28). Generally speaking, regardless of ancestry, age, or Suzuki grade, asymptomatic patients have improved long term outcomes suggesting that prompt diagnosis and early institution of preventative treatment modalities may be the most beneficial treatment strategy (22).

The cause of MD is unknown and thus mechanism specific prevention and reversal drug therapies are currently unavailable. The mainstay of medical management is based on the anti-platelet properties of Aspirin which prevents the ischemic complications of MD (2). The contemporary treatment strategy relies on both medical therapy and surgical revascularization $(8,15)$.

Surgical strategies depend on augmenting cerebral blood flow to the anterior cerebral circulation. Revascularization is the mainstay treatment for MD. Revascularization typically falls into two broad categories; indirect revascularization and direct revascularization. Hybrid procedures with combined direct and indirect bypasses have also been reported with good results $(4,13,27)$.

Indirect bypass procedures such as encephaloduroarteriomyosynangiosis and encephaloduroarteriorsynangiosis have been shown to resolve symptoms in a high proportion of patients (20). Direct bypass procedures such as STA to MCA bypass have also been equally effective. Some neurosurgeons favor one procedure over another while others use a combination of these techniques (11). Although there is evidence that support both indirect and direct revascularization techniques, unfortunately there is no Class I data comparing or recommending the use of one technique over another and thus the best strategy remains controversial.
By performing a review of recent literature we evaluated studies by Starke et al., Lin et al. and Bao et al. suggesting that modern indirect revascularization techniques carries a range of $73 \%$ to $91 \%$ overall success rate for adult patients with MD $(1,15,25)$. In these reports, the authors showed favorable functional outcomes as a mRS score of $0-2$ in up to $90 \%$ of patients undergoing EDAS. For adult patients undergoing indirect revascularization, post-operative ischemic strokes ranged from $16-18 \%$ despite higher risks of intracerebral hemorrhage in the adult Moyamoya population. Hemorrhagic complications were observed in only $2-4 \%$ of their study subjects $(1,15,25)$.

Direct revascularization refers to direct anastomosis commonly between the external carotid artery branches to the anterior or middle cerebral artery circulation. Direct bypass has the advantage of immediate revascularization to the affected territory. Direct bypass is generally performed with the frontal and parietal branches of the superficial temporal artery (STA), when suitable. This technique is technically more challenging and requires temporary clipping of MCA branches.

The first direct revascularization procedure for MD was performed by Yasargil and Yonekawa in 1972 and since then direct revascularization has been traditionally regarded as the treatment of choice for MD by many authors $(9,30)$.

Despite strong historical data to support its use in the pediatric population fewer papers have evaluated the efficacy of direct bypass in adults with MD. Guzman et al. reviewed their single-institution series of 233 adult patients and demonstrated more than $90 \%$ good functional outcome after STA-MCA bypass. In their series the risk of both ischemic and hemorrhagic complications were $3.4 \%$ each over a mean follow up of 4.9 years. Their results are contrary to the results of EDAS procedures which were dominated by ischemic complications (6). 
In 2014, Jiang et al. reported on a consecutive cohort of 113 patients undergoing 107 procedures from a single center with combined direct and indirect revascularization in adult patients with hemorrhagic MD and reported favorable outcomes in 99 out of 106 patients (93\%) (10). The authors also found a $1.9 \%$ re-hemorrhage rate at two year follow-up; however, patients presenting with post-operative ipsilateral re-hemorrhage had a mortality of 80 (10). Other series also support a high mortality rate in patients suffering postrevascularization hemorrhage in upwards of $50 \%$ (16). Despite high mortality rates from post-operative hemorrhages, overall, direct revascularization carries a high likelihood of good outcomes in patients with hemorrhagic MD. Direct bypass has been hypothesized to reduce the hemodynamic stress on fragile collateral vessels thus preventing recurrent hemorrhage; however, it is rational that post-procedural hemorrhages are more severe due to the increased cerebral perfusion (21).

There is variability regarding which form of revascularization is preferred. Most authors' preferred technique, whether direct, indirect, or combined, reflect their comfort level, training bias, and the patient specific anatomy. What is clear is that surgical revascularization outperforms medical management in reducing the risk of ischemic events, and surgical revascularization probably reduces the risk of hemorrhagic events, though the latter statement is more controversial.

The risk reduction of surgical revascularization in terms of hemorrhagic strokes has been less clear. The multicenter randomized Japan Adult Moyamoya (JAM) trial has reported a beneficial effect of bilateral direct bypass in reducing rehemorrhage in patients with previous hemorrhage within the last year, with an absolute risk reduction of $19.7 \%$ at 5 years; the annual risk of hemorrhage was reduced from $7.6 \%$ per year to $2.7 \%$ per year with bilateral direct bypass $(p=0.042)$ (18). It should be noted that surgical risk needs to be less than $7 \%$ to see this benefit clinically (4). Patients with a history of a hemorrhagic event should be offered revascularization because of the high risk of subsequent ischemic strokes, and the JAM trial suggests that risk reduction of hemorrhage can be reduced with direct bypass if the risk of surgical complications is low. Asymptomatic patients can be offered revascularization, and it should be strongly considered if there is abnormal cerebral perfusion or high frequency of pial collateralization.

The authors prefer direct double-barrel bypass and anastomosis with both the frontal and parietal branches of the STA to the MCA cortical branches if both donor and recipient arteries are suitable. This technique provides immediate revascularization, and seems to provide the greatest risk reduction for ischemic and hemorrhagic stroke.

\section{CONCLUSION}

MD is a progressive vascular disease that affects children and adults, causing ischemic and hemorrhagic strokes. Surgical intervention can reduce the risk of neurologic sequelae, both ischemic and hemorrhagic. There are numerous options for revascularization that include both direct and indirect revascularization. Direct double-barrel bypass from STA to MCA is our preferred technique and is supported by the literature to reduce both ischemic and hemorrhagic sequelae of MD when performed in experienced hands. However, in cases which one of the donor branches of the STA is hypoplastic or unsuitable - or if there are no fitting recipient arteries available for bypass - EDAS should be performed in conjunction with bypass as illustrated in our case presentation.

\section{REFERENCES}

1. Bao XY, Duan L, Li DS, Yang WZ, Sun WJ, Zhang ZS, Zong R, Han C: Clinical features, surgical treatment and long-term outcome in adult patients with Moyamoya disease in China. Cerebrovasc Dis 34:305-313, 2012

2. Bernard TJ, Goldenberg NA, Armstrong-Wells J, Amlie-Lefond C, Fullerton $\mathrm{H}$ : Treatment of childhood arterial ischemic stroke. Ann Neurol 63:679-696, 2008

3. Choi JU, Kim DS, Kim EY, Lee KC: Natural history of moyamoya disease: Comparison of activity of daily living in surgery and non surgery groups. Clin Neurol Neurosurg 99 Suppl 2:S1118,1997

4. Derdeyn CP: Direct bypass reduces the risk of recurrent hemorrhage in moyamoya syndrome, but effect on functional outcome is less certain. Stroke 45:1245-1246, 2014

5. Fung LW, Thompson D, Ganesan V: Revascularisation surgery for paediatric moyamoya: A review of the literature. Childs Nerv Syst 21:358-364, 2005

6. Guzman R, Lee M, Achrol A, Bell-Stephens T, Kelly M, Do HM, Marks MP, Steinberg GK: Clinical outcome after 450 revascularization procedures for moyamoya disease. Clinical article. J Neurosurg 111:927-935, 2009

7. Hallemeier $\mathrm{CL}$, Rich $\mathrm{KM}$, Grubb RL Jr, Chicoine MR, Moran CJ, Cross DT 3rd, Zipfel GJ, Dacey RG Jr, Derdeyn CP: Clinical features and outcome in North American adults with moyamoya phenomenon. Stroke 37:1490-1496, 2006

8. Ikezaki K: Rational approach to treatment of moyamoya disease in childhood. J Child Neurol 15:350-356, 2000

9. Ishikawa T, Houkin K, Kamiyama $\mathrm{H}$, Abe $\mathrm{H}$ : Effects of surgical revascularization on outcome of patients with pediatric moyamoya disease. Stroke 28:1170-1173, 1997

10. Jiang H, Ni W, Xu B, Lei Y, Tian Y, Xu F, Gu Y, Mao Y: Outcome in adult patients with hemorrhagic moyamoya disease after combined extracranial-intracranial bypass. J Neurosurg 15: $1-8,2014$

11. Khan N, Schuknecht B, Boltshauser E, Capone A, Buck A, Imhof HG, Yonekawa Y: Moyamoya disease and Moyamoya syndrome: Experience in Europe; choice of revascularisation procedures. Acta Neurochir 145:1061-1071, 2003

12. Kuroda S, Houkin K: Moyamoya disease: Current concepts and future perspectives. Lancet Neurol 7:1056-1066, 2008

13. Kuroda S, Houkin K: Bypass surgery for moyamoya disease: Concept and essence of sugical techniques. Neurol Med Chir 52:287-294, 2012 
14. Kuroda S, Ishikawa T, Houkin K, Nanba R, Hokari M, Iwasaki Y: Incidence and clinical features of disease progression in adult moyamoya disease. Stroke 36:2148-2153, 2005

15. Lin N, Aronson JP, Manjila S, Smith ER, Scott RM: Treatment of Moyamoya disease in the adult population with pial synangiosis. J Neurosurg 120:612-617, 2014

16. Liu X, Zhang D, Shuo W, Zhao Y, Wang R, Zhao J: Long term outcome after conservative and surgical treatment of haemorrhagic moyamoya disease. J Neurol Neurosurg Psychiatry 84:258-265, 2013

17. McLaughlin N, Martin NA: Effectiveness of burr holes for indirect revascularization in patients with moyamoya disease-a review of the literature. World Neurosurg 81:91-98, 2014

18. Miyamoto S, Yoshimoto $T$, Hashimoto N, Okada $Y$, Tsuji I, Tominaga T, Nakagawara J, Takahashi JC; JAM Trial Investigators. Effects of extracranial-intracranial bypass for patients with hemorrhagic moyamoya disease: Results of the Japan Adult Moyamoya Trial. Stroke 45:1415-1421, 2014

19. Olds MV, Griebel RW, Hoffman HJ, Craven M, Chuang S, Schutz $\mathrm{H}$ : The surgical treatment of childhood moyamoya disease. J Neurosurg 66:675-680, 1987

20. Ozgur BM, Aryan HE, Levy ML: Indirect revascularisation for paediatric moyamoya disease: The EDAMS technique. J Clin Neurosci 13:105-108, 2006

21. Ryan RW, Chowdhary A, Britz GW: Hemorrhage and risk of further hemorrhagic strokes following cerebral revascularization in Moyamoya disease: A review of the literature. Surg Neurol Int 3:72, 2012
22. Scott RM, Smith JL, Robertson RL, Madsen JR, Soriano SG, Rockoff MA: Long-term outcome in children with moyamoya syndrome after cranial revascularization by pial synangiosis. J Neurosurg 100 Suppl Pediatrics 2:142-149, 2004

23. Smith ER, Scott RM: Progression of disease in unilateral moyamoya syndrome. Neurosurg Focus 24:E17, 2008

24. Starke RM, Komotar RJ, Connolly ES: Optimal surgical treatment for moyamoya disease in adults: Direct versus indirect bypass. Neurosurg Focus 26:E8, 2009

25. Starke RM, Komotar RJ, Hickman ZL, Paz YE, Pugliese AG, Otten ML, Garrett MC, Elkind MS, Marshall RS, Festa JR, Meyers PM, Connolly ES Jr. Clinical features, surgical treatment, and long-term outcome in adult patients with moyamoya disease. Clinical article. J Neurosurg 111:936-942, 2009

26. Suzuki J, Kodama N: Moyamoya disease--a review. Stroke 14:104-109, 1983

27. Takahashi JC, Miyamoto S: Moyamoya disease: Recent progress and outlook. Neurol Med Chir 50:824-832, 2010

28. Wityk RJ, Hillis A, Beauchamp N, Barker PB, Rigamonti D: Perfusion-weighted magnetic resonance imaging in adult moyamoya syndrome: Characteristic patterns and change after surgical intervention: Case report. Neurosurgery 51:1499-1506, 2002

29. Yamada M: Moyamoya disease and intracranial hemorrhage. Nihon Rinsho 64 Suppl 8:524-528, 2006

30. Yasargil MG, Yonekawa Y: Results of microsurgical extraintracranial arterial bypass in the treatment of cerebral ischemia. Neurosurgery 1:22-24, 1977 